\title{
MYSTERY PHOTO
}

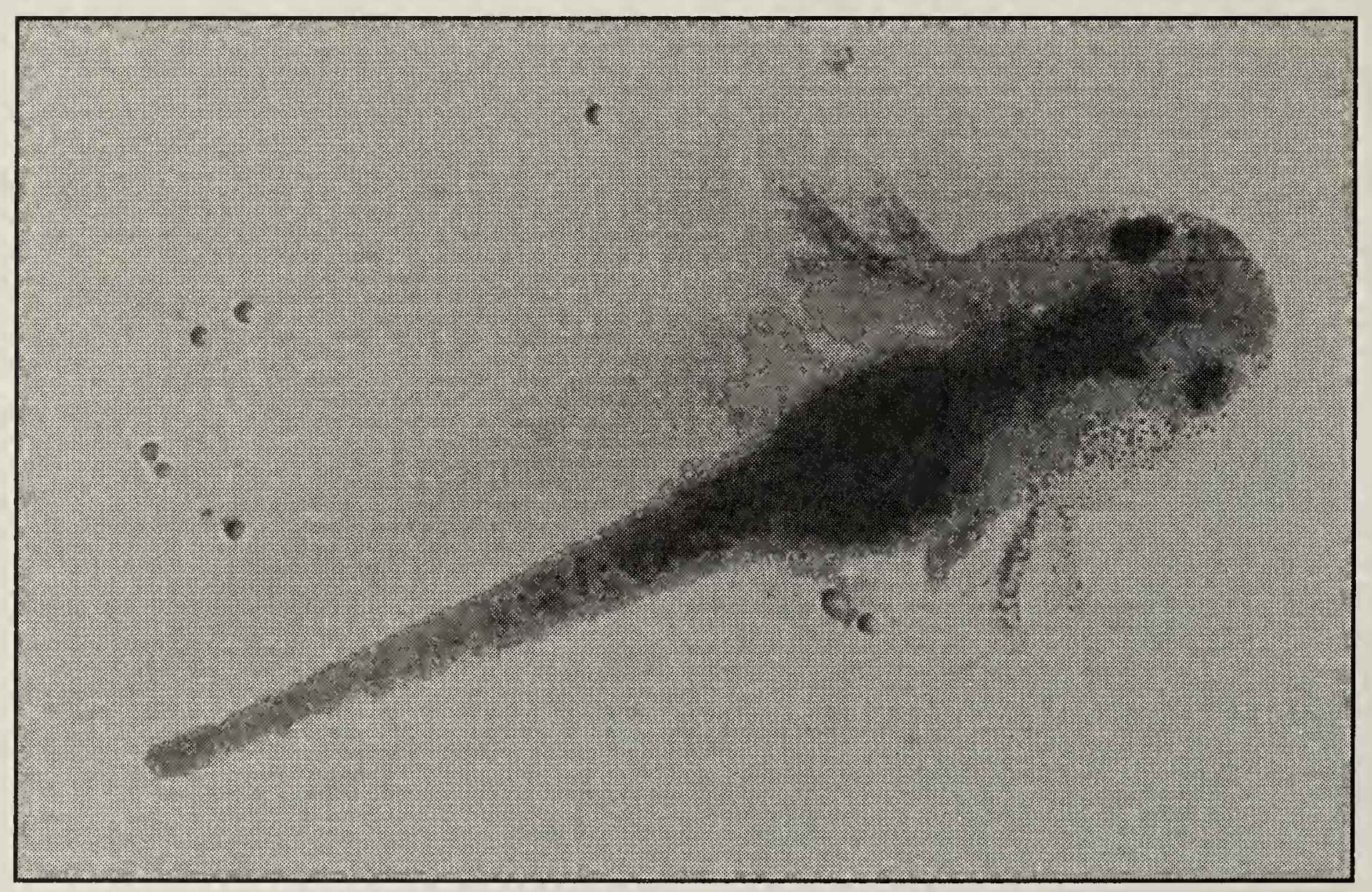

\section{SEPTEMBER 2001 MYSTERY PHOTO}

I am a wee beast from the slough, For whom dining on algae won't do!

Without 'frills' round my head,

I would surely be dead,

For I need to breath, just like you!

Photograph and limerick submitted by Danna Schock, photograph taken by Kathie Nordstrom.

Answer to JUNE 2001 MYSTERY PHOTO

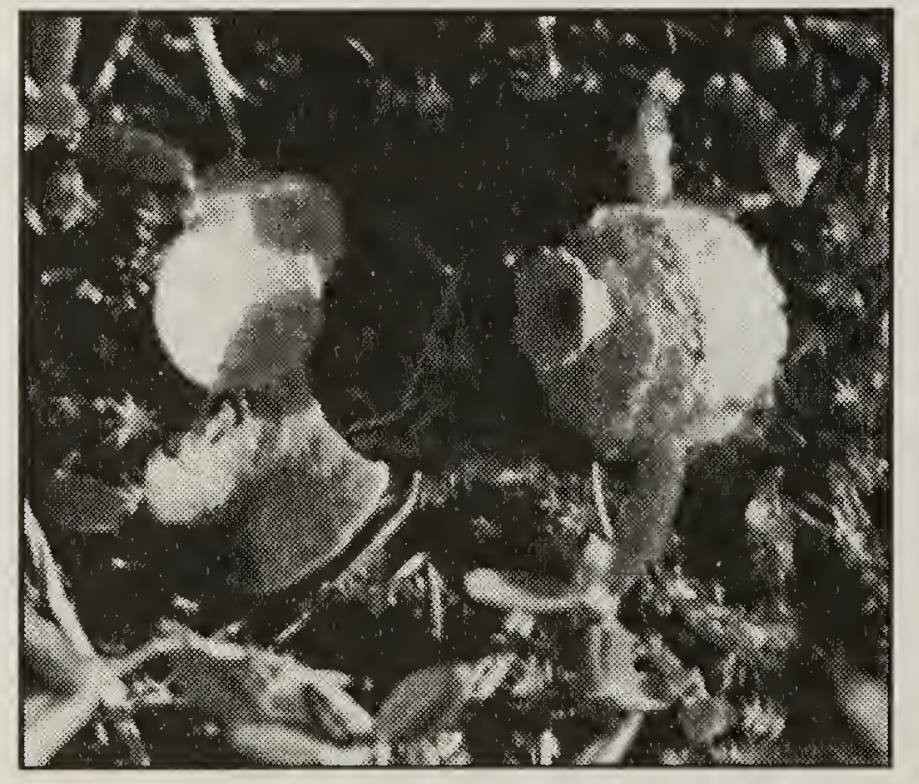

Lewis Bevan

The mystery object is a mud "pot", built on a twig or branch by a female Potter Wasp. She attaches an egg to the inside of the pot and provisions the pot with an anaesthetized caterpillar, as food for the wasp larva that will hatch out of the egg. Then the pot is sealed with mud and the young wasp must cut a hole to get out.

According to the Audubon Society Field Guide to North American Insects and Spiders by Lorus \& Margery Milne, 1980, "The provision chamber may 
be up to $1 / 2$ " (12 mm) wide. It is totally resistant to rain until the young wasp cuts an exit hole from the inside. Often several of these pot-like chambers appear on twigs." The subfamily Eumeninae (Mason \& Potter Wasps) of the family Vespidae includes 260 North American species at least, and most of them prey on caterpillars (Lepidoptera). (Borror, Triplehorn, \& White, 1992 (6 $6^{\text {th }}$ Ed.), An Introduction to the Study of Insects).
The editors would like to thank Jim Wolford for providing much of the information given above. Jim adds, "I think l've only seen one of these in the field, and we were very lucky to find an adult wasp (must have just emerged from the pupa) inside the pot, which was on a Blackberry bush stem on August 11,1980 , at White Rock, N.S. The wasp was mostly black, with a few white? or yellow? markings."

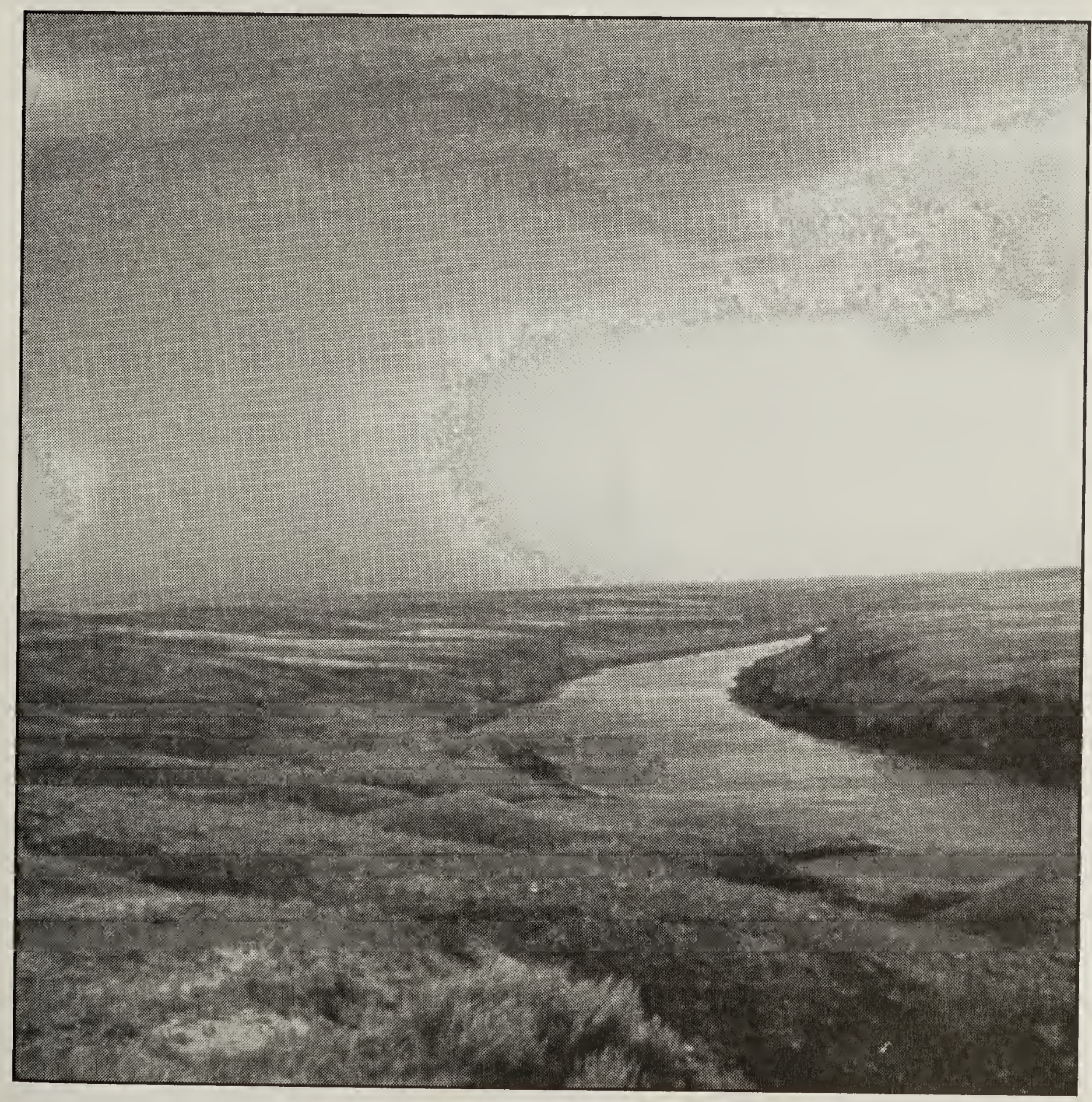

Storm over the South Saskatchewan River west of Leader, SK on August 17, 1981

Chris Adams 


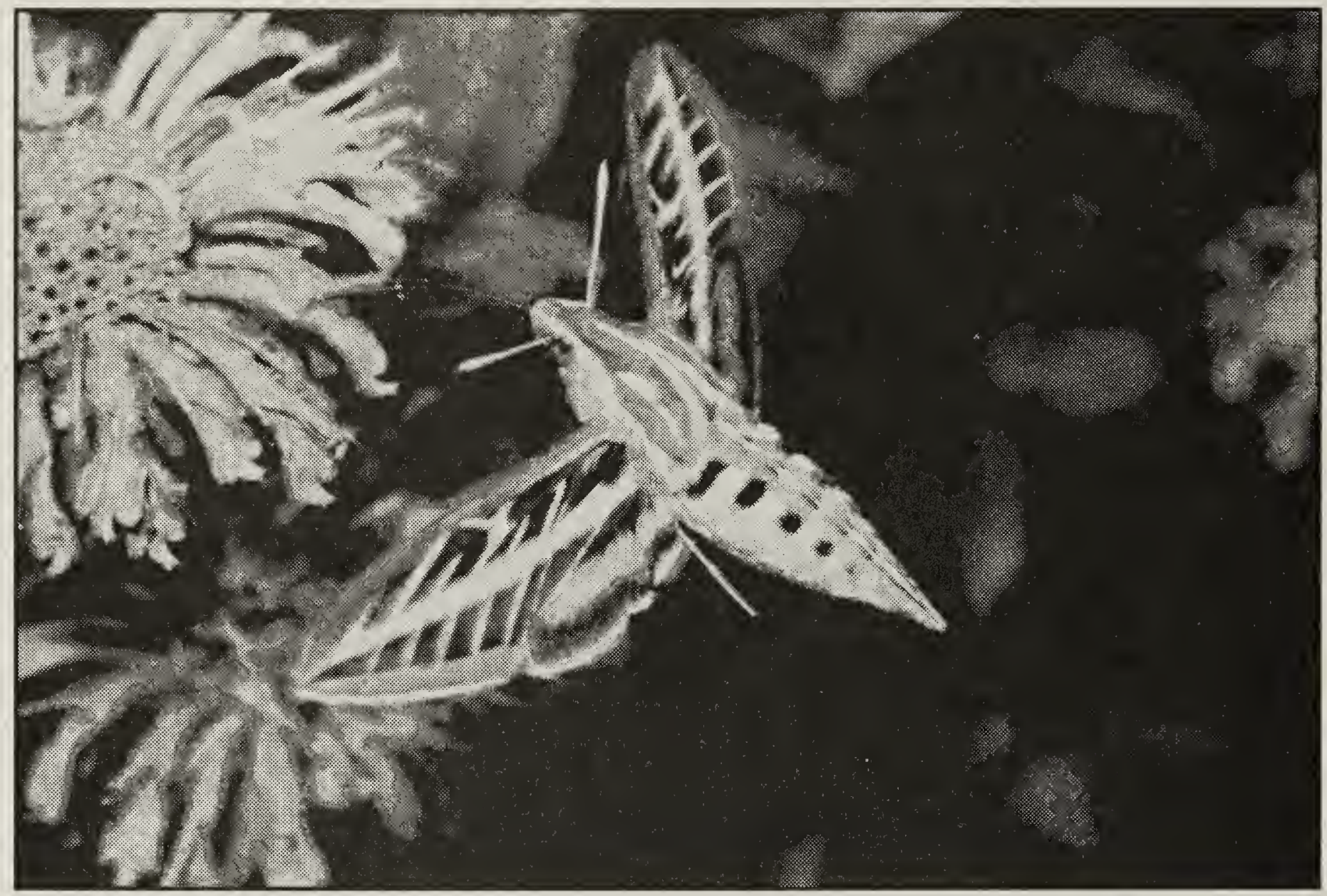

Striped Morning Sphinx

Fred Lahrman
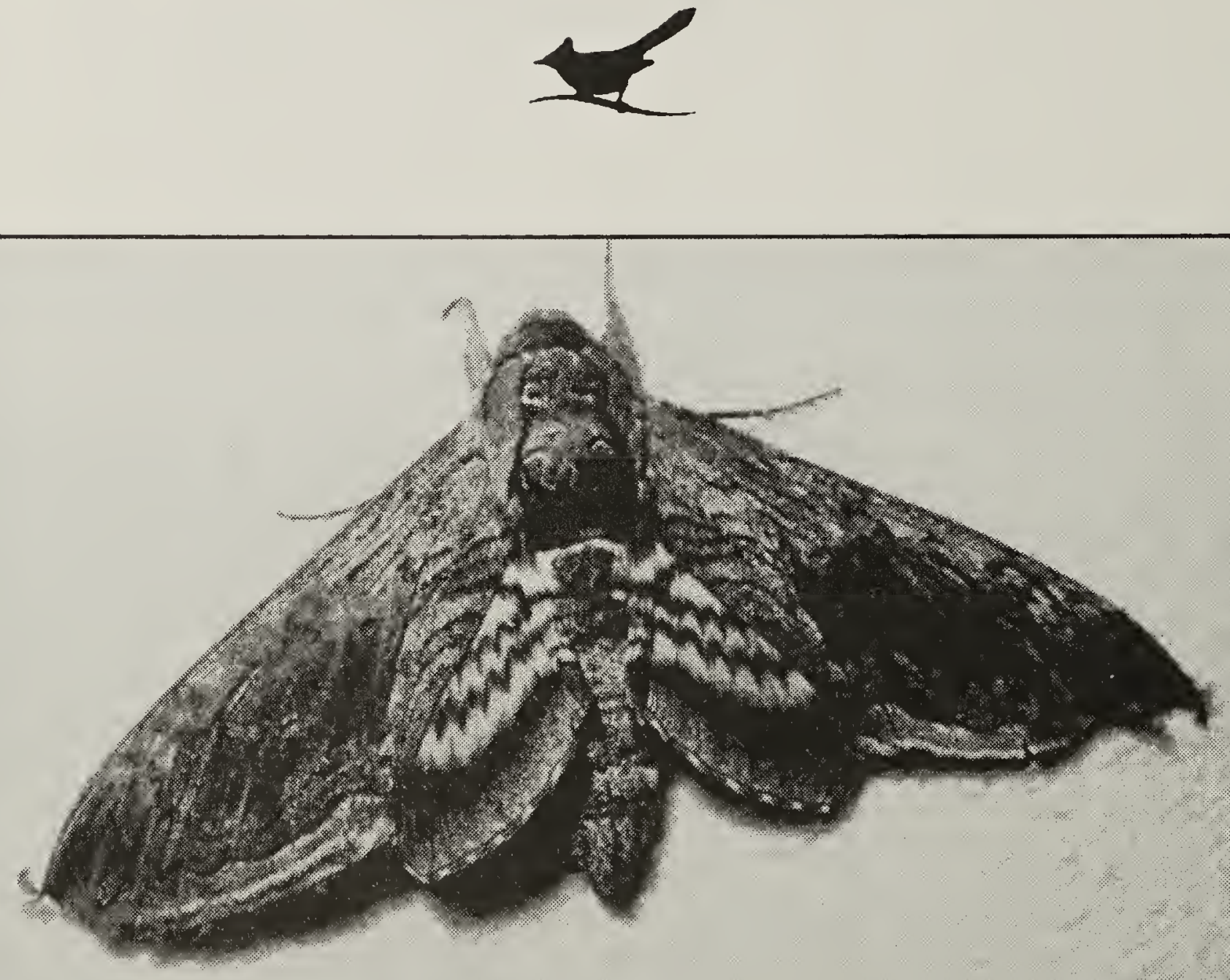